\title{
Lack of PKC $\theta$ Promotes Regenerative Ability of Muscle Stem Cells in Chronic Muscle Injury
}

\author{
Piera Filomena Fiore ${ }^{1,+}{ }^{,}$Anna Benedetti ${ }^{1}$, Martina Sandonà ${ }^{1,2}$, Luca Madaro ${ }^{1,2}$, \\ Marco De Bardi ${ }^{2}{ }^{(D}$, Valentina Saccone ${ }^{2,3}$, Pier Lorenzo Puri ${ }^{4}$, Cesare Gargioli ${ }^{5}(0)$ \\ Biliana Lozanoska-Ochser ${ }^{1}$ and Marina Bouché ${ }^{1, * \mathbb{D}}$ \\ 1 Department of AHFMO, University of Rome "la Sapienza", Via A. Scarpa 14, 00161 Rome, Italy; \\ pierafilomena.fiore@opbg.net (P.F.F.); anna.benedetti@uniroma1.it (A.B.); \\ martinasandona2@gmail.com (M.S.); luca.madaro@uniroma1.it (L.M.); \\ biliana.lozanoska-ochser@uniroma1.it (B.L.-O.) \\ 2 IRCCS Fondazione Santa Lucia (FSL), e00143 Rome, Italy; m.debardi@hsantalucia.it (M.D.B.); \\ v.saccone@hsantalucia.it (V.S.) \\ 3 Department of Life Sciences and Public Health, Università Cattolica del Sacro Cuore, 00168 Rome, Italy \\ 4 Development, Aging and Regeneration Program, Sanford Burnham Prebys Medical Discovery Institute, \\ La Jolla, CA 92037, USA; lpuri@sbpdiscovery.org \\ 5 Department of Biology, Tor Vergata University, 00133 Rome, Italy; Cesare.Gargioli@uniroma2.it \\ * Correspondence: marina.bouche@uniroma1.it; Tel.: +39-06-4976-6755 \\ † Present address: Immunology Area, Pediatric Hospital Bambino Gesù, 00165 Rome, Italy.
}

Received: 7 January 2020; Accepted: 29 January 2020; Published: 31 January 2020

\begin{abstract}
Duchenne muscular dystrophy (DMD) is a genetic disease characterized by muscle wasting and chronic inflammation, leading to impaired satellite cells (SCs) function and exhaustion of their regenerative capacity. We previously showed that lack of PKC $\theta$ in $m d x$ mice, a mouse model of DMD, reduces muscle wasting and inflammation, and improves muscle regeneration and performance at early stages of the disease. In this study, we show that muscle regeneration is boosted, and fibrosis reduced in $m d x \theta^{-/-}$mice, even at advanced stages of the disease. This phenotype was associated with a higher number of Pax7 positive cells in $m d x \theta^{-/-}$muscle compared with $m d x$ muscle, during the progression of the disease. Moreover, the expression level of Pax7 and Notch1, the pivotal regulators of SCs self-renewal, were upregulated in SCs isolated from $m d x \theta^{-/-}$muscle compared with $m d x$ derived SCs. Likewise, the expression of the Notch ligands Delta1 and Jagged1 was higher in $m d x \theta^{-/-}$ muscle compared with $m d x$. The expression level of Delta1 and Jagged1 was also higher in $\mathrm{PKC}^{-/-}$ muscle compared with WT muscle following acute injury. In addition, lack of PKC $\theta$ prolonged the survival and sustained the differentiation of transplanted myogenic progenitors. Overall, our results suggest that lack of $\mathrm{PKC} \theta$ promotes muscle repair in dystrophic mice, supporting stem cells survival and maintenance through increased Delta-Notch signaling.
\end{abstract}

Keywords: Duchenne Muscular Dystrophy; $m d x$; muscle satellite cells; Protein Kinase C $\theta$

\section{Introduction}

Duchenne muscular dystrophy (DMD) is a severe form of muscular dystrophy caused by lack of dystrophin, leading to membrane instability and increased probability of damage during contraction. As a result, dystrophic muscle is characterized by persistent inflammation, triggered by cycles of degeneration and regeneration. Chronic inflammation, in turn, impairs muscle regeneration and promotes the deposition of fibrotic and adipose tissue, which progressively replace the muscle tissue [1-3]. 
In DMD patients, the necrotic fibers are initially replaced by new fibers generated by satellite cells (SCs), the main myogenic stem cells in adult muscle. Upon muscle injury, SCs become activated, proliferate, and differentiate into myofibers while a minor subset self-renews to replenish the SCs pool [4]. Satellite cell self-renewal preserves the muscle regenerative capability following multiple injuries. Once activated, SCs can generate functionally different daughter cells by asymmetric division: One daughter will undergo differentiation after a variable number of symmetric cell divisions, while the other will return to the quiescent state. The "self-renewing" satellite cell is characterized by stable expression of Paired box 7 (Pax7), while the differentiating one upregulates Myogenic Differentiation1 (MyoD) expression and downregulates Pax7 [5,6].

In dystrophic muscle, the regeneration ability of SCs rapidly declines with age. In $m d x$ mice, a DMD animal model, muscle repair after injury is also impaired compared with WT mice, due to chronic inflammation and the exhaustion of the SCs pool [7-10]. Moreover, the decreased number of satellite cells in dystrophic muscle during aging has been linked to impaired Notch signaling. Notch signaling is involved in regulation of satellite cell activation and self-renewal. Notch 1, 2, and 3 are expressed in quiescent SCs, while muscle fibers are the major source of Notch ligands, such as Delta and Jagged [11-13]. Notch activation prevents myogenic differentiation and promotes satellite cell self-renewal, by upregulating Pax7 and inhibiting MyoD [14,15]. In the absence of Notch, SCs undergo accelerated terminal differentiation without self-renewal, resulting in muscle stem cell pool depletion [16].

In $m d x$ mice, activation of the Notch pathway rescued the self-renewal ability of satellite cells [17]. Intriguingly, in a canine model of DMD, two Golden Retriever muscular dystrophy (GRMD) dogs, were found to suffer a milder dystrophic phenotype. This milder phenotype was correlated to increased Jagged1 expression, suggesting that promoting Notch signaling may represent a therapeutic approach for DMD in a dystrophin-independent manner [18].

We previously showed that lack or pharmacological inhibition of PKC $\theta$ reduced muscle loss and inflammation, and increased muscle regeneration and performance in $m d x$ mice. The observed phenotype was primarily due to lack of PKC $\theta$ in hematopoietic cells $[19,20]$, and in particular inhibition of early T cells infiltration in dystrophic muscle [21]. However, PKC $\theta$ is also expressed in muscle, where it modulates several signalling pathways involved in foetal and early post-natal tissue growth and maturation [22-24]. Intriguingly, we observed enhanced muscle regeneration in dystrophic muscle lacking PKC $\theta$, compared to $m d x$, and reduced muscle necrosis and fibrosis, suggesting that PKC $\theta$ might also regulate SC function during disease progression. Here we show that lack of PKC $\theta$ in $m d x$ mice improves the survival and maintenance of both endogenous and transplanted stem cells, most likely by promoting Notch signaling.

\section{Results}

\subsection{Lack of PKCO in Mdx Mice Boosts Muscle Regeneration While Reducing Muscle Fiber Degeneration}

The progression of the dystrophic pathology in mdx mice follows distinct phases of muscle degeneration and regeneration. Up until two weeks of age, the muscle morphology is similar in $m d x$ and WT mice. Muscle fiber degeneration in mdx mice becomes evident at around 3 weeks of age and peaks at 4 weeks. The high level of muscle degeneration is then followed by high level of muscle regeneration. By 3 months of age, the cycles of both degeneration and regeneration are attenuated, and the skeletal muscle enters a stable phase $[25,26]$.

To further understand the eventual role of $\mathrm{PKC} \theta$ in regulating muscle regeneration and satellite cells function in dystrophic muscle, we first analyzed the histo-pathological features, in terms of the extent of muscle degeneration and regeneration, in $m d x \theta^{-/-}$mice compared to $m d x$, during the progression of the disease, from 1 to 12 months of age. Muscle degeneration was evaluated in tibialis anterior (TA) muscle by H\&E (Supplementary Figure S1), while muscle regeneration was evaluated by embryonic myosin heavy chain (eMHC) immunostaining (Supplementary Figure S2). The results, 
summarized in Figure 1A, show a peak in muscle damage at 4 weeks as expected, with a sharp drop by 6 weeks of age; after this age, muscle damage continued to slowly decrease, up to 12 months of age. Similarly, the high level of muscle regeneration (Figure 1B) observed at 4 weeks of age, dropped drastically by 6 weeks and remained low until 12 months of age. By contrast, the level of muscle damage was much lower in 4-week-old $m d x$ mice lacking PKC $\theta$ compared to $m d x$, as previously shown [22], and this low level was maintained throughout the ages studied, besides a slight increase at 6 months of age. Consistently, the level of muscle regeneration was lower in 4-week-old $m d x / \theta^{-/-}$compared to $m d x$, but this level was maintained throughout the 12-month time period. Expressing these results as the ratio of regenerating area over damaged area (Figure 1C), we found that in $m d x \theta^{-/-}$muscle the ratio is higher at all the ages examined, suggesting that the regeneration process is boosted compared to $m d x$ during the progression of the disease, independently from the level of muscle damage.

A

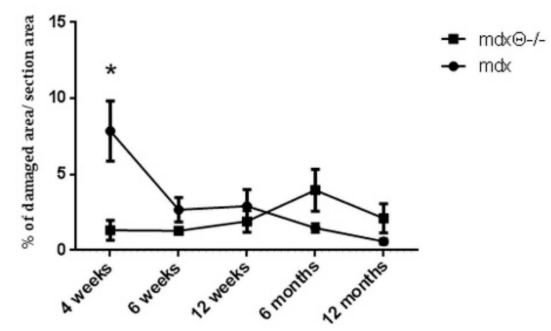

B

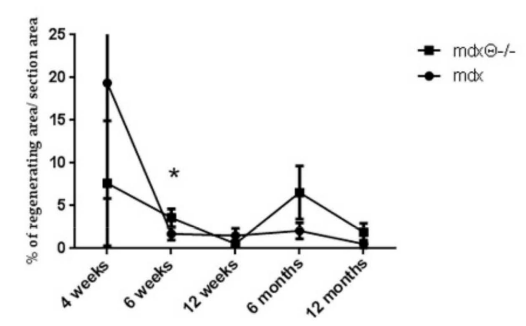

$\mathrm{D}$
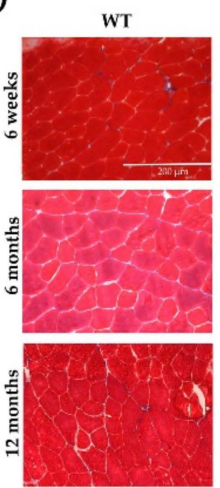

mdx

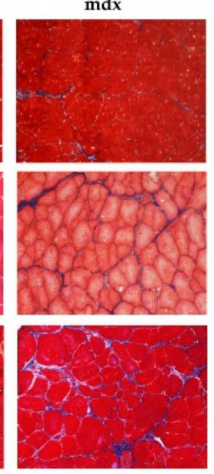

mdx $\Theta-/-$

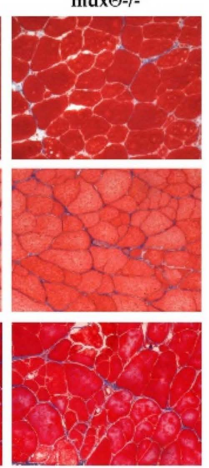

C

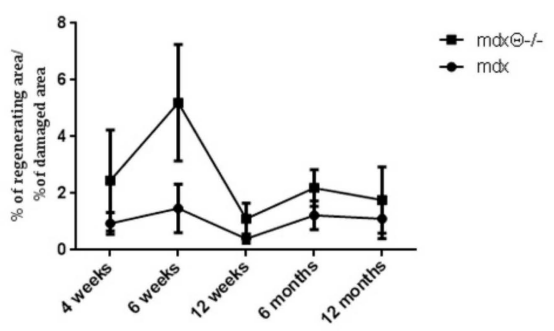

E

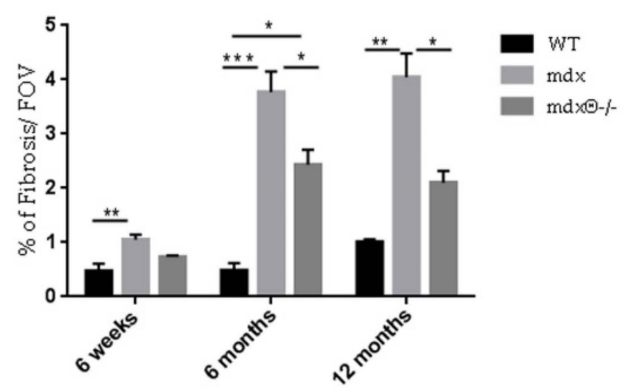

Figure 1. (A) Muscle degeneration level evaluated in $m d x$ or $m d x / \theta^{-/-}$mice at the indicated ages, quantified as the percentage of damaged area over the total area in H\&E stained TA cryosections. (B) Muscle regeneration as in A, quantified as the percentage of eMHC positive area over total area of TA cryosections. (C) Ratio of regenerating area over damaged area determined in $m d x$ and $m d x / \theta^{-/-}$ mice at each age evaluated. The results are mean $\pm \operatorname{SEM}\left(n=4-5 /\right.$ age/genotype); ${ }^{*} p<0.05$ two-tailed Student's $t$-test). (D) Representative images of Masson's trichrome staining of cryosections derived from WT/bl10, $m d x$ and $m d x \theta^{-/-}$TA muscle at 6 weeks, 6 and 12 months $(\mathrm{bar}=200 \mu \mathrm{m})$. (E) Fibrosis was quantified as the percentage of Masson's trichrome positive area per field of view in TA section. Statistical significance was determined by a one-way ANOVA using a Tukey's post-test $\left({ }^{*} p<0.05,{ }^{* *} p\right.$ $<0.01,{ }^{* * *} p<0.001$ means $\pm \mathrm{SD}$ ).

During disease progression, chronic damage and inflammation are known to prevent adequate regeneration leading to increased ECM deposition and fibrotic tissue accumulation, which is one 
of the most deleterious aspects of DMD. The Masson's trichrome staining of TA sections (Figure 1) showed that the increased collagen deposition observed in $\mathrm{mdx}$ mice during the progression of the disease, compared to WT mice, is significantly reduced when PKC $\theta$ is absent, at all the ages examined. These findings suggest that lack of PKC $\theta$ reduces muscle necrosis and fibrosis and improves regeneration.

\subsection{Dystrophic Muscle Repair After Injury is Enhanced in The Absence of PKCO}

The repeated cycles of degeneration and regeneration and the hostile dystrophic environment are believed to exhaust the regenerative capacity of SCs. Indeed, after acute injury, the muscle repair is impaired in $m d x$ mice compared with WT mice [27] and worsens over time [7]. Therefore, we wondered whether lack of PKC $\theta$ may improve the regenerative ability of dystrophic muscle following injury. TA muscle of 6-month-old $m d x$ and $m d x \theta^{-/-}$mice were injured by intra-muscular cardiotoxin (CTX) injection. Age- and sex-matched WT mice were used for comparison. The mice were sacrificed 7 days after CTX injection, and the number of regenerating myofibers, identified as centrally nucleated fibers, was counted in H\&E stained sections of TA muscles (Figure 2A). As shown in Figure 2B, a significantly higher number of regenerating fibers was found in TA muscle derived from $m d x \theta^{-/-}$mice compared with $m d x$, almost restoring the number of regenerating fibers found in injured WT muscle. Skeletal muscle repair following injury requires the deposition, remodeling, and reorganization of ECM. ECM deposition occurs within a week post-injury, and it can continue for several weeks to ensure complete repair. However, in the case of chronic injuries, such as in dystrophic muscle, the newly generated ECM can turn into scar tissue [28]. As shown in Figure 2C, 7 days after CTX injury, the amount of ECM deposition in the injured area was greater in $m d x$ mice compared to WT mice, as expected. Interestingly, lack of PKC $\theta$ significantly reduced ECM deposition in mdx mice. Together, these results suggest that in the absence of $\mathrm{PKC} \theta$, dystrophic muscle preserves the ability of skeletal muscle to repair the damaged area.

A
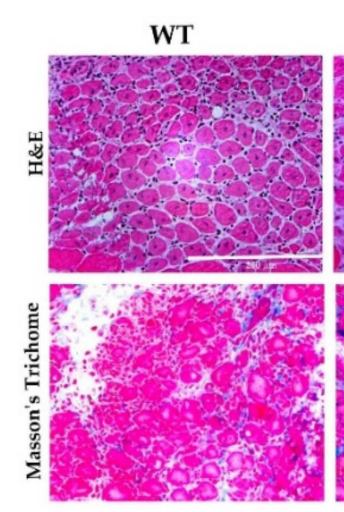
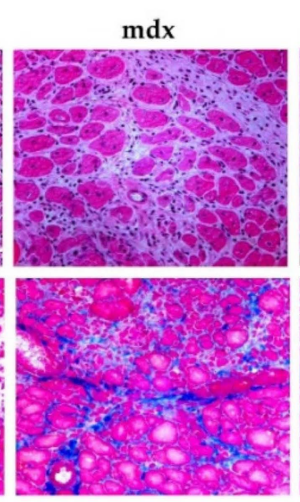

mdx $\theta-/-$

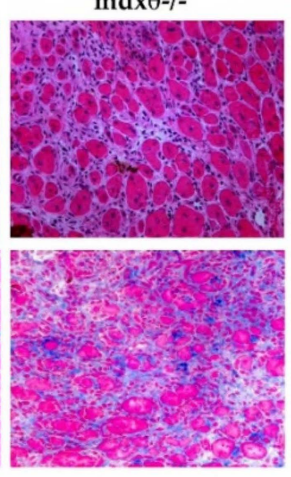

B

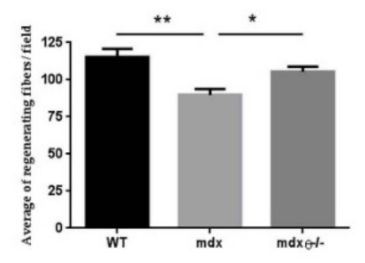

C

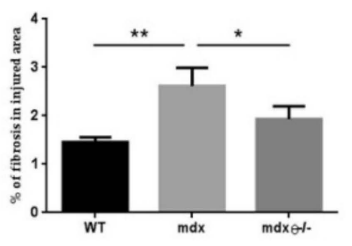

Figure 2. (A) Representative image of TA stained with H\&E (upper panels) and Masson's trichrome staining (lower panels) of 6- month-old WT/bl10 $(n=3), m d x$ and $m d x \theta^{-/-}$mice $(n=5 /$ genotype), as indicated, at day 7 after CTX injury (bar $=200 \mu \mathrm{m})$. (B) Average of number of regenerating fibers and

(C) Quantification of collagen deposition per field of view. Statistical significance was determined by a one-way ANOVA using a Tukey's post-test $\left(* p<0.05,{ }^{* *} p<0.01\right.$, means $\left.\pm \mathrm{SD}\right)$.

\subsection{Lack of PKCO in Mdx Mice Preserves the Self-Renewal Ability of Satellite Cells}

Given the reduction of muscle damage during the early stages of the disease in $m d x \theta^{-/-}$, we wondered whether the enhanced repair ability was due to a more efficient maintenance of the SC pool compared with $m d x$ mice. Indeed, in muscular dystrophy the continuous rounds of damage can exhaust the self-renewal ability of satellite cells [27]. In the early stages of the muscle repair 
process, quiescent SCs migrate to the site of injury and proliferate. Following the proliferation phase, a subset of SCs undergoes myogenic differentiation, downregulating Pax7 expression and upregulating MyoD expression. Another subset of proliferating SCs maintains Pax7 expression, and returns to a quiescent state, ensuring renewal of the SC pool [29-31]. First, TA section from $m d x$ and $m d x \theta^{-/-}$mice were immuno-stained for Pax7 and Laminin expression at different ages (Supplementary Figure S3). The counting of the number of total Pax7 positive cells in each condition revealed that it was significantly higher in TA muscle from $m d x \theta^{-/-}$compared to $m d x$ mice at all the ages examined (Figure 3A). Next, we performed qRT-PCR analysis and found that the level of expression of Myogenin at later stages of the disease (12 months of age), was higher in $m d x \theta^{-/-}$mice compared to $m d x$ mice (Figure 3B), suggesting that lack of PKC $\theta$ improves SCs ability to repair damaged muscle. Myogenin expression is upregulated in differentiating satellite cells, and it is considered a marker of muscle regeneration [32]. This increase was not observed in muscle derived from $\mathrm{PKC}^{-/-}$as compared with WT, suggesting that it is a consequence of lack of PKC $\theta$ specifically in a dystrophic environment (Figure 3B).

A

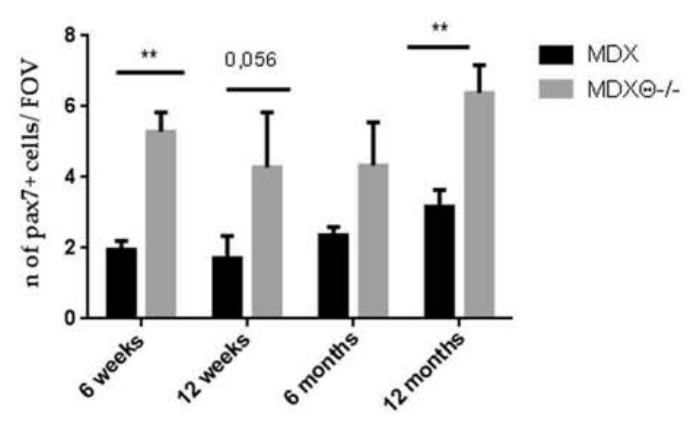

B

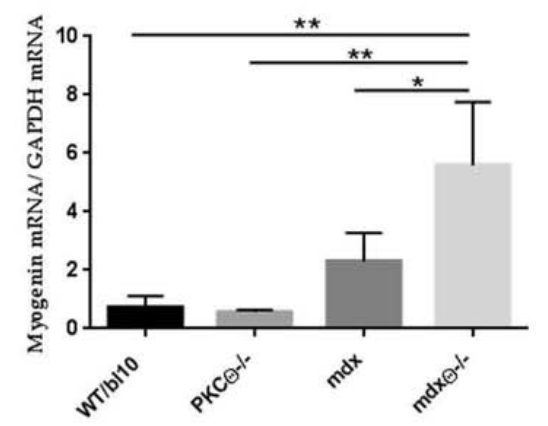

Figure 3. (A) Number of Pax7+ cells in TA section of $m d x$ and $m d x \theta^{-/-}$mice at 6 and 12 weeks, and 6 and 12 months of age. The number of Pax $7^{+}$cells was calculated by counting the number of PAX7 $7^{+}$ cells per field of view in immune-stained sections. The results are the means $\pm \mathrm{SD}(n=3 /$ genotype/ age ${ }^{*} p<0.05,{ }^{* *} p<0.01$, two-tailed Student's $t$-test). (B) Myogenin mRNA levels in WT $(n=2)$, PKC $\theta^{-/-}(n=3), m d x(n=5)$ and $m d x \theta^{-/-}(n=4)$ TA muscle from 12 months old mice. The values were normalized vs. GAPDH mRNA level of expression. Statistical significance was determined by a one-way ANOVA using a Tukey's post-test $\left({ }^{*} p<0.05\right.$, means $\left.\pm \mathrm{SD}\right)$.

Together, these results suggest that lack of PKC $\theta$ preserves the SCs pool in dystrophic muscle even at advanced ages, without affecting the balance between self-renewal and myogenic commitment.

\subsection{The Self-Renewal Ability of Satellite Cells in $\mathrm{mdx} \theta^{-/-}$Muscle is Maintained and Supported by Up-Regulation of Notch-Signaling}

To further characterize the effect of lack of PKC $\theta$ on dystrophic SCs activity, FACS-isolated SCs from limb muscle of 6-week-old $m d x$ and $m d x \theta^{-/-}$mice were cultured in vitro. We chose 6 weeks of age because this is the age when muscle regeneration starts to decline in $m d x$ muscle. After 62 $\mathrm{h}$ in culture, the cells were analyzed for the expression of Pax7 and MyoD by immunofluorescence. Based on the expression of Pax7 and MyoD, cultured satellite cells are defined as self-renewing $\left(\mathrm{Pax}^{+} / \mathrm{MyoD}^{-}\right)$, activated $\left(\mathrm{Pax}^{+} / \mathrm{MyoD}^{+}\right)$or differentiating $\left(\mathrm{Pax}^{-} / \mathrm{MyoD}^{+}\right)$[5,33]. As shown in Figure 4, the percentage of $\mathrm{Pax}^{+} / \mathrm{MyoD}^{-}$"self-renewing" cells over the total number of $\mathrm{Pax} 7^{+}$cells, was higher in SCs derived from $m d x \theta^{-/-}$muscle compared to $m d x$. 
A

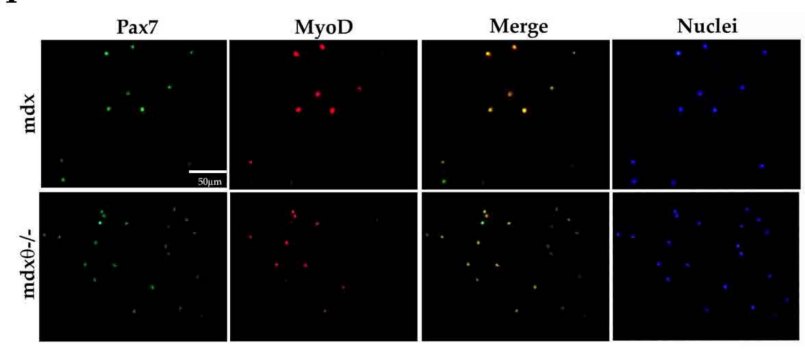

B

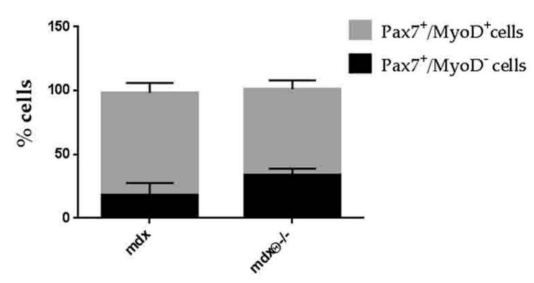

Figure 4. (A) Representative image of Pax7 (green) and MyoD (red) immunofluorescence of SCs, isolated from $\mathrm{mdx}$ and $m d x \theta^{-/-}$muscle and cultured for $62 \mathrm{~h}$. Nuclei were counterstained with Hoechst (blue) (bar $=50 \mu \mathrm{m})$. (B) Percentages of $\mathrm{Pax}^{+} / \mathrm{MyoD}^{-}$and $\mathrm{Pax} 7^{+} / \mathrm{MyoD}^{+}$cells over the total number of nuclei. The results are mean $\pm S \mathrm{D})(n=3$ /genotype).

Next, we analyzed the expression level of genes involved in SC self-renewal (Pax7, MyoD, Notch1-2-3, Delta1, and Numb) in freshly FACS-sorted SCs, by qRT-PCR analysis. As shown in Figure 5A, Pax7 and Notch1 level of expression was significantly higher in SCs freshly isolated from $m d x \theta^{-/-}$mice compared with those isolated from $m d x$ mice. Notch signaling in SCs is activated by the binding of the Notch receptor to the Jagged1 and Delta1 ligands expressed on the myofiber surface. It is known that Delta1 expression decreases in aged and dystrophic muscle [7,34]. As shown in Figure 5B, Delta1 level of expression is significantly higher in TA muscle derived from $m d x \theta^{-/-}$compared to $m d x$ muscle at 6 and 12 weeks, as well as at 12 months of age (Figure 5B). Also, Jagged1 level of expression is higher in TA muscle derived from 6 week and 12 months old $m d x \theta^{-/-}$mice, compared to muscle from age-matched $m d x$ mice (Figure 5B). The high level of expression of Notch ligands in $m d x \theta^{-/-}$ muscle may suggest an active role of myofibers to boost the self-renewal process.

Interestingly, we found that, although Delta1 and Jagged1 level of expression was similar in healthy WT and $\mathrm{PKC}^{-/-}$non-dystrophic muscle (Supplementary Figure S4), upon acute injury, at day 3 after CTX-injection, the level of expression of Jagged 1 was significantly higher in $\mathrm{PKC}^{-/-}$muscle compared to WT. Conversely, the expression level of Delta1 was higher in $\mathrm{PKC}^{-/-}$muscle compared to WT at day 7 after injury (Figure 5C). These results suggest that the increased Notch ligands expression observed in injured muscle lacking PKC $\theta$ might favor SCs self-renewal, even in non-dystrophic setting. 
A

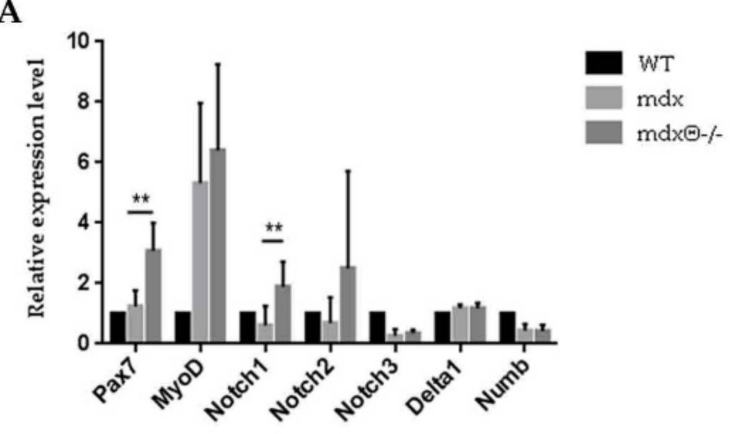

B
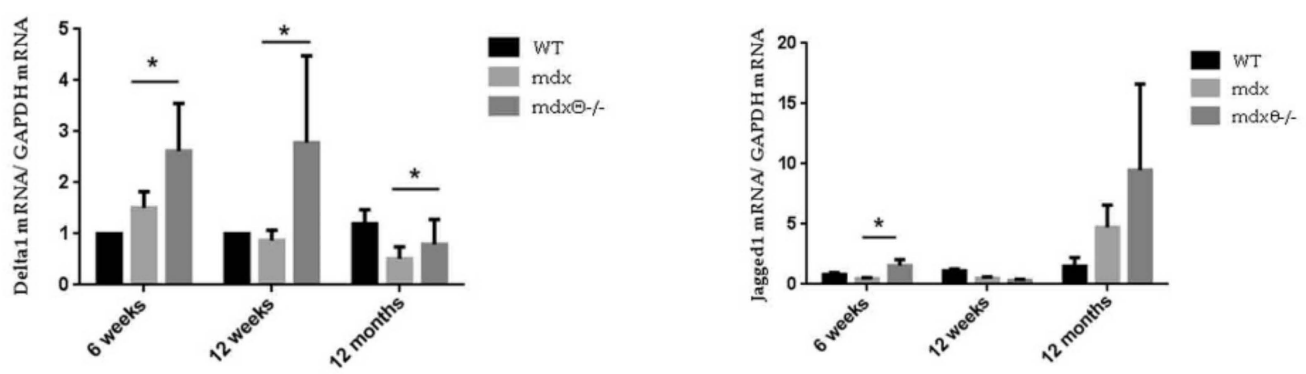

C
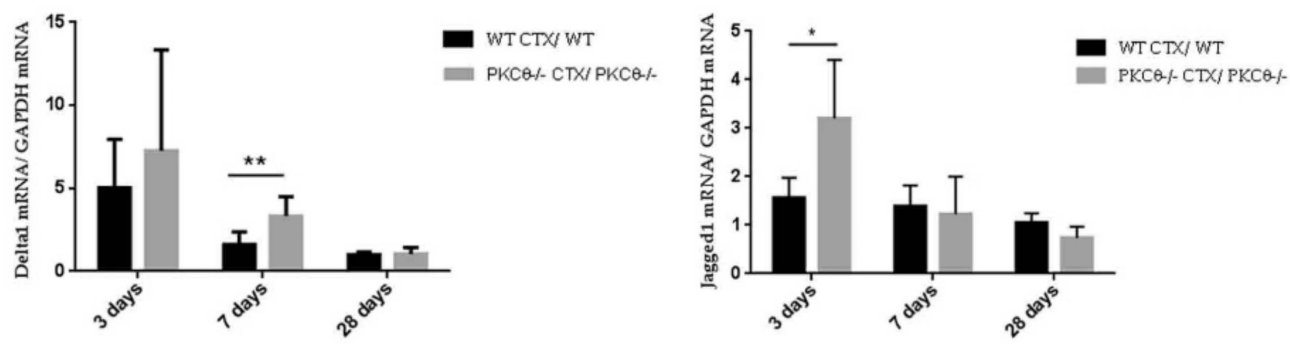

Figure 5. (A) Sorted SCs were analyzed for the level of expression of Pax7, MyoD, Notch receptors, Delta1, and Numb by qRT-PCR. RNA expression level in $\mathrm{mdx}$ and $m d x \theta^{-/-}$SCs was normalized against GAPDH. Samples represent three pooled RNA from SCs sorted from three mice for each sample. ${ }^{*} p<$ $0.05,{ }^{* *} p<0.01$, two-tailed Student's $t$-test). (B) Delta1 and Jagged1 mRNA level in mdx and $m d x \theta^{-/-}$ TA ( $n=4-7 /$ genotype/age). ( ${ }^{*} p<0.05$, two-tailed Student's $t$-test). (C) Ratio of Delta1 and Jagged1 mRNA level between injured and contralateral uninjured TA muscle in WT/bl6 and PKC $\theta^{-/-}$at 3, 7 and 28 days after CTX injury ( $n=4-6 /$ genotype).

2.5. Lack of PKC $\theta$ Supports Transplanted Stem Cells Survival and Differentiation in Injured and Dystrophic Muscle

To further verify whether lack of PKC $\theta$ in muscle imparts a regenerative advantage, we analyzed the survival and engraftment of transplanted stem cells in both dystrophic and non-dystrophic mice lacking PKC $\theta$. To this aim, we used mouse Mesoangioblasts (MABs), myogenic progenitor cells, as exogenous stem cells. Indeed, Notch signaling has been shown to potentiate mesoangioblasts (MABs)-driven regeneration in vivo [35].

Mouse nLacZ-expressing MABs $\left(5 \times 10^{5}\right)$ [36] were transplanted via intra-muscular injection into TA muscle of WT and PKC $\theta^{-/-}$mice, injured with CTX $24 \mathrm{~h}$ previously. The mice were sacrificed 3, 7, and 14 days after transplantation. As shown in Figure 6A, the number of nLacZ-MABs within the injured muscle was similar in WT and $\mathrm{PKC}^{-/-}$mice up to 7 days after transplantation. Interestingly, 14 days after transplantation, nLacZ-MABs were detectable in TA muscle derived from PKC $\theta^{-/-}$mice, but not in WT. Moreover, although resolution of regeneration was slower in $\mathrm{PKC} \theta^{-/-}$mice, as already 
described [22], LacZ positive nuclei were localized within muscle fibers, showing that the transplanted MABs contributed to the formation of regenerating myofibers.
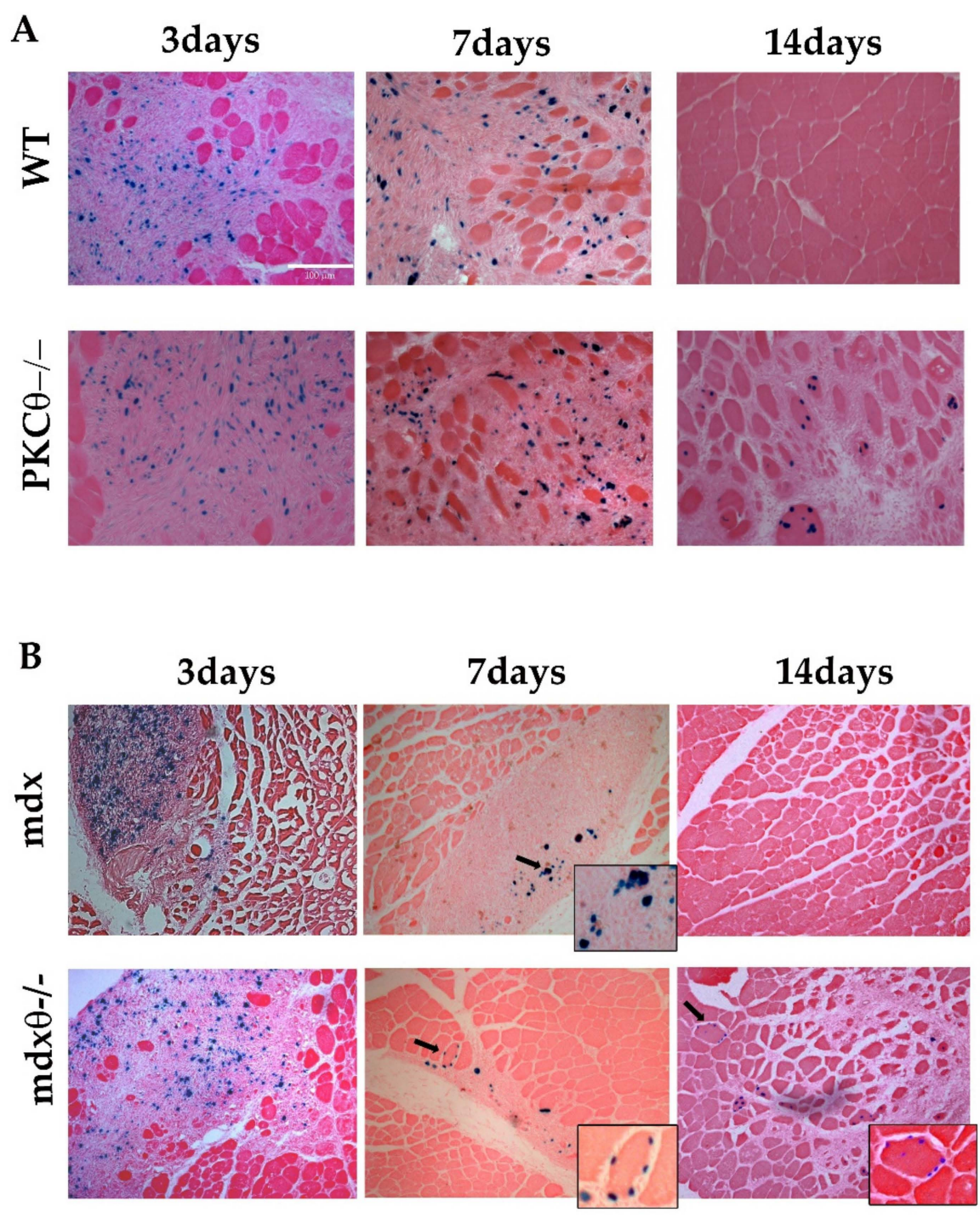

Figure 6. (A) Representative cryosections of TA muscle derived from WT and $\mathrm{PKC}^{-/-}$sacrificed 3, 7 , or 14 days after transplantation ( $n=3-5 /$ genotype, each time point), as indicated, and processed for X-gal activity (bar $=100 \mu \mathrm{m}$ ). (B) Representative cryosections of TA muscle derived from $m d x$ and $m d x \theta^{-/-}$sacrificed 3, 7 or 14 days after transplantation, ( $n=3-5 /$ genotype, each time point), as indicated, and processed for X-gal activity. Small side pictures show higher magnification of parts of the sections. Arrows indicate X-gal positive nuclei included within some fibers in PKC $\theta$-null mice, in both non-dystrophic and dystrophic background.

We then analyzed the survival of transplanted MABs in dystrophic muscle. MABs were transplanted via intra-muscular injection in TA muscle of 6-week-old $m d x$ and $m d x \theta^{-/-}$mice. The mice were sacrificed 3, 7, and 14 days after transplantation. As in the non-dystrophic background, the number of nLacZ/MABs within the muscle was similar in $m d x$ and $m d x \theta^{-/-}$mice 3 and 7 days after transplantation. Interestingly, while LacZ positive nuclei in $m d x$ muscle were mostly localized in the interstitium, in $m d x \theta^{-/-}$muscle they were mostly found within myofibers, even after only 7 days after transplantation (Figure 6B). These results suggest that the muscle environment in $m d x \theta^{-/-}$mice improves MABs ability to fuse with muscle fibers compared to $m d x$ mice. Importantly, 14 days after transplantation, nLacZ/MABs were detected in muscle derived from $m d x \theta^{-/-}$mice, but not from 
$m d x$ mice. Together, these results demonstrate that lack of PKC $\theta$ prolongs the survival and supports differentiation and engraftment of transplanted MABs.

\section{Discussion}

The present study shows that lack of PKC $\theta$ in $m d x$ mice improves muscle repair and promotes satellite cell pool maintenance. We previously showed that lack of PKC $\theta$ reduced muscle damage and inflammation and increased muscle performance in 8-week-old $m d x$ mice [19]. Here, we show that the high level of muscle damage observed in $m d x$ mice is almost blunted in $m d x \theta^{-/-}$mice throughout the late disease stages. Moreover, collagen deposition was reduced in $m d x \theta^{-/-}$compared to $m d x$ mice. Surprisingly, the area of regenerating myofibers was similar between the two genotypes, at all ages examined, suggesting that lack of PKC $\theta$ promotes muscle regeneration in dystrophic muscle. Increased regeneration was also observed after acute injury, supporting the hypothesis that the myogenic ability of endogenous cell populations is maintained and promoted in the absence of PKC $\theta$. These results might appear in contrast to our previous observation that lack of PKC $\theta$ delayed muscle repair after freeze-injury in a non-dystrophic background. However, the observed delay in muscle repair was not associated with a reduced differentiation activity of satellite cells, nor with changes in cell growth rate, but with a delay in the addition of fusing cells to regenerating myofibers, a process known as "secondary fusion" [22]. On the other hand, in the dystrophic background, compromised muscle repair is due to impaired satellite cells activation and maintenance. Thus, the different muscle regenerative abilities of $m d x$ and $m d x \theta^{-/-}$could be due to the different behavior of satellite cells due to the different quality of the environment. We show that lack of PKC $\theta$ prevents the early peak of muscle degeneration in $m d x$, which, in turn, may prevent the exhaustion of satellite cell pool and preserve their self-renewal ability. Indeed, the number of Pax7 positive cells in muscle is higher in $m d x \theta^{-/-}$mice compared to $m d x$ mice, and the level of Pax7 and Notch1 expression in satellite cells isolated from $m d x \theta^{-/-}$muscle is higher than in SCs from $m d x$. Notch1 signaling is required for the maintenance of the regenerative ability and self-renewal of satellite cells. It is well known that Notch signaling declines in aged mice and in muscular dystrophy $[7,34]$. Notch signaling is activated by the binding of Delta or Jagged ligands to Notch receptors at the level of the cell membrane. After injury, Notch ligands are upregulated on the myofiber surface, suggesting that the activation of Notch signaling is crucial during muscle repair. Satellite cells are directly associated with the myofiber surface, and Notch ligands on myofibers should activate Notch signaling in satellite cells. Interestingly, we found that in $m d x \theta^{-/-}$muscle, Delta1 and Jagged1 expression is higher than in $m d x$ muscle, suggesting that the myofibers could support Notch signaling in satellite cells. In basal conditions, PKC $\theta$ does not affect Delta1 and Jagged1 expression level; in fact, their expression is similar in WT and $\mathrm{PKC}^{-/-}$muscle. In contrast, after acute injury, the level of Delta1 expression is higher in $\mathrm{PKC}^{-/-}$muscle compared to WT muscle, suggesting that PKC $\theta$ could directly affect Delta1 and Jagged1 expression level after injury. This observation suggests that the up regulation of Delta1 and Jagged1 expression is due to lack of PKC $\theta$ in myofibers and not to different muscle environment. In fact, $\mathrm{PKC} \theta$ is crucial for the adaptive immune response in chronic muscle injury where T cells are involved but, in acute muscle injury, lack of PKC $\theta$ does not alter the innate immune response (myeloid cell recruitment) that is important during the regenerating process [21].

Interestingly, lack of PKC $\theta$ in $m d x$ promotes not only the regenerative activity of endogenous myogenic cell populations, but also the regenerative activity of exogenous transplanted stem cells. In fact, lack of PKC $\theta$ in $m d x$ muscle improved MABs survival and differentiation in myofibers. Even at 14 days after transplantation, MABs were still detectable in $m d x \theta^{-/-}$muscle and were incorporated into myofibers; by contrast, in $m d x$ muscle MABs were detectable up to seven days post-transplantation, and mostly in the interstitial space. It is conceivable that lack of PKC $\theta$ modifies the inflammatory environment, thus favoring MABs survival and differentiation ability. Moreover, since PKC $\theta$ is involved in allograft responses, its lack may partly prevent cell rejection. Our mice were not immune-suppressed, and, although the MABs used derived from the same genetic background, they express beta-gal, which is highly immunogenic. Further, the improved MABs myogenic differentiation within $m d x \theta^{-/-}$muscle, 
may also depend, at least in part, to the observed increase in Delta1 expression on myofibers. Indeed, the Dll1-Notch1 axis regulates the myogenic potential of MABs and ameliorates in vivo MAB-driven regeneration [35].

Together, our results suggest that lack of PKC $\theta$ in dystrophic muscle creates a more favorable environment for both endogenous and exogenous cell populations to contribute to muscle maintenance and repair. Although this phenotype is partly dependent on modifications in the quality of the immune response, the results shown here suggest that PKC $\theta$ activity might also directly regulate muscle cell populations phenotype and behavior, contributing to the exhaustion of the satellite cell active pool. Finally, these findings improve our understanding of the molecular mechanisms underlying satellite cell pool maintenance in muscular dystrophy paving the way for the design of efficient pharmacological therapeutic strategies aimed at enhancing muscle repair.

\section{Materials and Methods}

\subsection{Animal Models}

PKC $\theta^{-/-}$mice (C57BL/6J background) were previously described [22,37]. Mdx mice (C57BL/10ScSn-Dmdmdx/J) were purchased from Jackson laboratory (Bar Harbor, Main, USA) and $m d x \theta^{-/-}$transgenic mice were generated in our laboratory (C57BL/6j-C57BL/10ScSn background) [19]. C57BL/10ScSn control mice were purchased from Jackson laboratory. Only males were used. The animals were housed in the Histology Department-accredited animal facility. All the procedures were approved by the Italian Ministry for Health and were conducted according to the U.S. National Institutes of Health (NIH) guidelines.

\subsection{Muscle Injury Procedure}

To induce muscle injury, $10 \mu \mathrm{L}$ of $10 \mu \mathrm{mol}$ cardiotoxin solution (Sigma-Aldrich, Saint Louis, MI, USA) was injected in two different area of the TA using a 30 Gauge micro syringe.

\subsection{Mesangioblast Transplantation}

Animals were anesthetized with Avertin (Sigma-Aldrich). Intramuscular injection was performed in TA with $5 \times 10^{5}$ cells/50 $\mu \mathrm{L}$ saline solution, using 30-gauge needles.

\subsection{Histochemistry and Immunofluorescence Analyses}

For histochemistry and immunofluorescence analyses, TA muscles were dissected, embedded in tissue-freezing medium (Leica, Richmond, IL, USA), and snap-frozen in liquid nitrogen-cooled isopentane. Frozen muscle was cut into $7-\mu \mathrm{m}$ cryosections. For histological analysis, the sections were stained with hematoxylin/eosin or with Masson's trichrome stain (both from Sigma-Aldrich); for X-galactosidase staining, cryosections were fixed in $0.1 \%$ glutaraldehyde, $\beta$-galactosidase ( $\beta G A L$ ) activity in mice transplanted TA muscles was revealed in transverse cryosections using X-galactosidase (Qiagen, Hilden, Germany). For immunostaining, permeabilization in methanol (6 min at $220^{\circ} \mathrm{C}$ ) was performed on cryosections after fixation. A citric acid antigen retrieval protocol was used to facilitate PAX7 staining [33]. In brief, slides were heated in a $90{ }^{\circ} \mathrm{C}$ solution of 0.01 Mcitric acid ( $\mathrm{pH}$ 6) for $10 \mathrm{~min}$ and followed by $2 \%$ bovine serum albumin block in PBS. Sections were incubated with primary antibodies for Pax7 (DSHB, University of Iowa, Iowa City, USA; 1:20), Laminin (Sigma-Aldrich; 1:100). Antibody binding was revealed using species-specific secondary antibodies coupled to Alexa Fluor 488 (Life Technologies, Carlsbad, CA, USA), Cy3or Cy5 (Jackson Immunoresearch, West Grove, PA, USA). Nuclei were counterstained with Hoechst 33342 (Thermo Fisher Scientific, Waltham, MA, USA).

The sections were photographed in a Zeiss Axioskop 2 Plusfluorescence microscope, and the images were analyzed using Image J software. 


\subsection{Cell Cultures}

Muscle satellite cells (SCs) were prepared from limb skeletal muscles, as previously described [38]. Briefly, dissected muscles were chopped and then digested with $2 \mu \mathrm{g} / \mathrm{mL}$ Collagenase A, $2.4 \mathrm{U} / \mathrm{mL}$ Dispase I, $10 \mathrm{ng} / \mathrm{mL}$ DNase I (all from F. Hoffmann-La Roche Ltd., Basel, Switzerland), $0.4 \mathrm{mM} \mathrm{CaCl2,}$ and $5 \mathrm{mM} \mathrm{MgCl} 2$ for $90 \mathrm{~min}$ at $37^{\circ} \mathrm{C}$. After digestion, the obtained cell suspension was washed with Dulbecco's phosphate-buffered saline (DPBS) containing 0,2\% BSA and then filtered through 70 and then $40 \mu \mathrm{m}$ cell strainer. Cells were incubated with the mix of the appropriate primary antibodies $(10 \mathrm{ng} / \mathrm{mL})$ CD31-PacificBlue (Invitrogen, Carisbad, CA, USA), CD45-eFluor450, Ter119-eFluor450, CD34-Biotin (all from eBioscience, Wien, Österreich), CD11b-Pacific blue, Sca-1-FITC (BD Bioscience, San Jose, CA, USA), and $\alpha 7$ integrin-APC (kindly provided by Dr. Fabio Rossi) for $30 \mathrm{~min}$ on ice. A subsequent incubation, $30 \mathrm{~min}$ on ice, with Streptavidin-PE-Cy7 (1/500; BD Bioscience) was performed. Cells were finally washed and resuspended in HBSS containing $0.2 \% w / v$ BSA and $1 \% v / v$ Penicillin-Streptomycin. Cell sorting were performed on a Beckman Coulter MoFlo High Speed Sorter (Software Summit V4.3.01). SCs were isolated as Ter119-/CD45-/CD31-/CD34+/ $\alpha 7-$ integrin+/Sca-1- cells. We were performed flow cytometry analysis through FlowJo software (Software FlowJo, LLC, Treestar, CA, USA, v. 10.4.2). SCs were grown on gelatin-coated dishes, in GM (DMEM containing $20 \%$ horse serum, HS, $3 \%$ chick embryo extract, $\mathrm{EE}$, all from Invitrogen, Carlsbad, CA) in a humidified $5 \% \mathrm{CO}_{2}$ atmosphere at $37^{\circ} \mathrm{C}$.

nLacZMabs: nLacZ-Mabs derived from C57/b16 mice [36], were grown in Dulbecco's modified Eagle medium (DMEM) supplemented with 10\% FCS (both from Gibco; Invitrogen, Carlsbad, CA, USA) in a humidified $5 \% \mathrm{CO} 2$ atmosphere at $37^{\circ} \mathrm{C}$.

\subsection{RNA Extraction, cDNA Synthesis and qRT-PCR}

For RNA isolation from cells, the cells were collected in TRIsureTM (Bioline, London, UK) according to the manufacturer's instructions. For RNA preparation from muscle, the muscles were homogenized in TRIsure with the ULTRA-TURRAX T25 (IKA ${ }^{\circledR}$-Werke GmbH \& Co. KG, Staufen, Germany) and syringed 4 times with a $21 \mathrm{G}$ needle syringe. The RNA was converted in cDNA by a RT PCR. For the RT PCR, the High-Capacity cDNA RT kit from Applied Biosystem (Foster City, CA, USA) was used. For RT-qPCR analysis, the BiolineSensiMixTM SYBR Low-ROX Kit (Bioline) was used, following the manufacturer's protocol. For data analysis, the 75000 Software v2.0.5, provided by Applied Biosystem, was used. Primer list are reported in Supplementary Table S1.

\subsection{Statistical Analysis}

Sample size used is indicated in the legend of each Figure. Quantitative data are presented as means \pm SD or means \pm SEM of at least three different experiments. Statistical analysis to determine significance was performed using unpaired Student's $t$ tests or one-way ANOVA with Tukey's multiple comparisons, when appropriate. Differences were considered statistically significant at the $p \leq$ 0.05 level.

\section{Conclusions}

In conclusion, our results suggest that PKC $\theta$ activity directly regulate muscle cell populations phenotype and behavior, contributing to the exhaustion of the satellite cell active pool in pathological conditions, such as in muscular dystrophy. Indeed, its lack in dystrophic muscle creates a more favorable environment for both endogenous and exogenous cell populations, promoting muscle maintenance and repair. These findings open new and exciting perspectives to the design of novel pharmacological strategies aimed at enhancing muscle repair in pathological conditions.

Supplementary Materials: Supplementary materials can be found at http://www.mdpi.com/1422-0067/21/3/932/s1.

Author Contributions: Conceptualization, P.F.F., L.M., C.G., and M.B.; data curation, P.F.F. and M.B.; formal analysis, P.F.F.; funding acquisition, M.B.; investigation, P.F.F., A.B., M.S., and M.D.B.; project administration, M.B.; 
resources, L.M., M.D.B., V.S., P.L.P., C.G., and M.B.; supervision, V.S., P.L.P., C.G., B.L.-O., and M.B.; validation, P.F.F., A.B., and M.S.; writing-original draft, P.F.F. and M.B.; writing—review \& editing, P.F.F., B.L.-O., and M.B. All authors have read and agreed to the published version of the manuscript.

Funding: This research was funded by grants from Telethon (grant No GGP13233), Sapienza University of Rome and Parent Project, Italy to MB, Sapienza University of Rome "Starting grant" to P.F. and M.S.

Conflicts of Interest: The authors declare no conflict of interest.

\section{Abbreviations}

$\begin{array}{ll}\text { DMD } & \text { Duchenne muscular Dystrophy } \\ \text { SCs } & \text { Satellite Cells } \\ \text { PKC } \theta & \text { Protein Kinase C } \theta \\ \text { Pax7 } & \text { Paired box 7 } \\ \text { MyoD } & \text { Myogenic Differentiation1 } \\ \text { GRMD } & \text { Golden Retriever Muscular Dystrophy } \\ \text { eMyHC } & \text { embryonic Myosin Heavy Chain } \\ \text { TA } & \text { Tibialis Anterior } \\ \text { ECM } & \text { ExtraCellular Matrix } \\ \text { CTX } & \text { Cardiotoxin } \\ \text { MABs } & \text { Mesoangioblasts }\end{array}$

\section{References}

1. Christov, C.; Chretien, F.; Abou-Khalil, R.; Bassez, G.; Vallet, G.; Authier, F.J.; Bassaglia, Y.; Shinin, V.; Tajbakhsh, S.; Chazaud, B.; et al. Muscle satellite cells and endothelial cells: Close neighbors and privileged partners. Mol. Biol. Cell 2007, 18, 1397-1409. [CrossRef]

2. Madaro, L.; Bouche, M. From innate to adaptive immune response in muscular dystrophies and skeletal muscle regeneration: The role of lymphocytes. BioMed Res. Int. 2014, 2014, 438675. [CrossRef] [PubMed]

3. Pessina, P.; Kharraz, Y.; Jardi, M.; Fukada, S.; Serrano, A.L.; Perdiguero, E.; Munoz-Canoves, P. Fibrogenic Cell Plasticity Blunts Tissue Regeneration and Aggravates Muscular Dystrophy. Stem Cell Rep. 2015, 4, 1046-1060. [CrossRef] [PubMed]

4. Yin, H.; Price, F.; Rudnicki, M.A. Satellite cells and the muscle stem cell niche. Physiol. Rev. 2013, 93, $23-67$. [CrossRef] [PubMed]

5. Zammit, P.S.; Golding, J.P.; Nagata, Y.; Hudon, V.; Partridge, T.A.; Beauchamp, J.R. Muscle satellite cells adopt divergent fates: A mechanism for self-renewal? J. Cell Biol. 2004, 166, 347-357. [CrossRef]

6. Olguin, H.C.; Olwin, B.B. Pax-7 up-regulation inhibits myogenesis and cell cycle progression in satellite cells: A potential mechanism for self-renewal. Dev. Biol. 2004, 275, 375-388. [CrossRef]

7. Jiang, C.; Wen, Y.; Kuroda, K.; Hannon, K.; Rudnicki, M.A.; Kuang, S. Notch signaling deficiency underlies age-dependent depletion of satellite cells in muscular dystrophy. Dis. Models Mech. 2014, 7, 997-1004. [CrossRef]

8. Delaporte, C.; Dehaupas, M.; Fardeau, M. Comparison between the growth pattern of cell cultures from normal and Duchenne dystrophy muscle. J. Neurol. Sci. 1984, 64, 149-160. [CrossRef]

9. Sacco, A.; Mourkioti, F.; Tran, R.; Choi, J.; Llewellyn, M.; Kraft, P.; Shkreli, M.; Delp, S.; Pomerantz, J.H.; Artandi, S.E.; et al. Short telomeres and stem cell exhaustion model Duchenne muscular dystrophy in $\mathrm{mdx} / \mathrm{mTR}$ mice. Cell 2010, 143, 1059-1071. [CrossRef]

10. Reimann, J.; Irintchev, A.; Wernig, A. Regenerative capacity and the number of satellite cells in soleus muscles of normal and mdx mice. Neuromuscul. Disord. 2000, 10, 276-282. [CrossRef]

11. Mourikis, P.; Tajbakhsh, S. Distinct contextual roles for Notch signalling in skeletal muscle stem cells. BMC Dev. Biol. 2014, 14, 2. [CrossRef] [PubMed]

12. Pasut, A.; Chang, N.C.; Gurriaran-Rodriguez, U.; Faulkes, S.; Yin, H.; Lacaria, M.; Ming, H.; Rudnicki, M.A. Notch Signaling Rescues Loss of Satellite Cells Lacking Pax7 and Promotes Brown Adipogenic Differentiation. Cell Rep. 2016, 16, 333-343. [CrossRef] [PubMed]

13. Low, S.; Barnes, J.L.; Zammit, P.S.; Beauchamp, J.R. Delta-Like 4 Activates Notch 3 to Regulate Self-Renewal in Skeletal Muscle Stem Cells. Stem Cells 2018, 36, 458-466. [CrossRef] [PubMed] 
14. Wen, Y.; Bi, P.; Liu, W.; Asakura, A.; Keller, C.; Kuang, S. Constitutive Notch activation upregulates Pax7 and promotes the self-renewal of skeletal muscle satellite cells. Mol. Cell. Biol. 2012, 32, 2300-2311. [CrossRef]

15. Fujimaki, S.; Seko, D.; Kitajima, Y.; Yoshioka, K.; Tsuchiya, Y.; Masuda, S.; Ono, Y. Notch1 and Notch2 Coordinately Regulate Stem Cell Function in the Quiescent and Activated States of Muscle Satellite Cells. Stem Cells 2018, 36, 278-285. [CrossRef]

16. Bjornson, C.R.; Cheung, T.H.; Liu, L.; Tripathi, P.V.; Steeper, K.M.; Rando, T.A. Notch signaling is necessary to maintain quiescence in adult muscle stem cells. Stem Cells 2012, 30, 232-242. [CrossRef]

17. Mann, C.J.; Perdiguero, E.; Kharraz, Y.; Aguilar, S.; Pessina, P.; Serrano, A.L.; Munoz-Canoves, P. Aberrant repair and fibrosis development in skeletal muscle. Skeletal Muscle 2011, 1, 21. [CrossRef]

18. Vieira, N.M.; Elvers, I.; Alexander, M.S.; Moreira, Y.B.; Eran, A.; Gomes, J.P.; Marshall, J.L.; Karlsson, E.K.; Verjovski-Almeida, S.; Lindblad-Toh, K.; et al. Jagged 1 Rescues the Duchenne Muscular Dystrophy Phenotype. Cell 2015, 163, 1204-1213. [CrossRef]

19. Madaro, L.; Pelle, A.; Nicoletti, C.; Crupi, A.; Marrocco, V.; Bossi, G.; Soddu, S.; Bouche, M. PKC theta ablation improves healing in a mouse model of muscular dystrophy. PLoS ONE 2012, 7, e31515. [CrossRef]

20. Marrocco, V.; Fiore, P.; Benedetti, A.; Pisu, S.; Rizzuto, E.; Musaro, A.; Madaro, L.; Lozanoska-Ochser, B.; Bouche, M. Pharmacological Inhibition of PKCtheta Counteracts Muscle Disease in a Mouse Model of Duchenne Muscular Dystrophy. EBioMedicine 2017, 16, 150-161. [CrossRef]

21. Lozanoska-Ochser, B.; Benedetti, A.; Rizzo, G.; Marrocco, V.; Di Maggio, R.; Fiore, P.; Bouche, M. Targeting early PKCtheta-dependent T-cell infiltration of dystrophic muscle reduces disease severity in a mouse model of muscular dystrophy. J. Pathol. 2018, 244, 323-333. [CrossRef]

22. Madaro, L.; Marrocco, V.; Fiore, P.; Aulino, P.; Smeriglio, P.; Adamo, S.; Molinaro, M.; Bouche, M. PKCtheta signaling is required for myoblast fusion by regulating the expression of caveolin-3 and beta1D integrin upstream focal adhesion kinase. Mol. Biol. Cell 2011, 22, 1409-1419. [CrossRef]

23. Messina, G.; Biressi, S.; Monteverde, S.; Magli, A.; Cassano, M.; Perani, L.; Roncaglia, E.; Tagliafico, E.; Starnes, L.; Campbell, C.E.; et al. Nfix regulates fetal-specific transcription in developing skeletal muscle. Cell 2010, 140, 554-566. [CrossRef]

24. Zappelli, F.; Willems, D.; Osada, S.; Ohno, S.; Wetsel, W.C.; Molinaro, M.; Cossu, G.; Bouche, M. The inhibition of differentiation caused by TGFbeta in fetal myoblasts is dependent upon selective expression of PKCtheta: A possible molecular basis for myoblast diversification during limb histogenesis. Dev. Biol. 1996, 180, 156-164. [CrossRef]

25. Evans, N.P.; Misyak, S.A.; Robertson, J.L.; Bassaganya-Riera, J.; Grange, R.W. Dysregulated intracellular signaling and inflammatory gene expression during initial disease onset in Duchenne muscular dystrophy. Am. J. Phys. Med. Rehabil. 2009, 88, 502-522. [CrossRef]

26. McGreevy, J.W.; Hakim, C.H.; McIntosh, M.A.; Duan, D. Animal models of Duchenne muscular dystrophy: From basic mechanisms to gene therapy. Dis. Models Mech. 2015, 8, 195-213. [CrossRef]

27. Irintchev, A.; Zweyer, M.; Wernig, A. Impaired functional and structural recovery after muscle injury in dystrophic mdx mice. Neuromuscul. Disord 1997, 7, 117-125. [CrossRef]

28. Garg, K.; Corona, B.T.; Walters, T.J. Therapeutic strategies for preventing skeletal muscle fibrosis after injury. Front. Pharmacol. 2015, 6, 87. [CrossRef]

29. Zammit, P.S.; Heslop, L.; Hudon, V.; Rosenblatt, J.D.; Tajbakhsh, S.; Buckingham, M.E.; Beauchamp, J.R.; Partridge, T.A. Kinetics of myoblast proliferation show that resident satellite cells are competent to fully regenerate skeletal muscle fibers. Exp. Cell Res. 2002, 281, 39-49. [CrossRef]

30. Halevy, O.; Piestun, Y.; Allouh, M.Z.; Rosser, B.W.; Rinkevich, Y.; Reshef, R.; Rozenboim, I.; Wleklinski-Lee, M.; Yablonka-Reuveni, Z. Pattern of Pax7 expression during myogenesis in the posthatch chicken establishes a model for satellite cell differentiation and renewal. Dev. Dyn. 2004, 231, 489-502. [CrossRef]

31. Day, K.; Shefer, G.; Richardson, J.B.; Enikolopov, G.; Yablonka-Reuveni, Z. Nestin-GFP reporter expression defines the quiescent state of skeletal muscle satellite cells. Dev. Biol. 2007, 304, 246-259. [CrossRef] [PubMed]

32. Zammit, P.S.; Relaix, F.; Nagata, Y.; Ruiz, A.P.; Collins, C.A.; Partridge, T.A.; Beauchamp, J.R. Pax7 and myogenic progression in skeletal muscle satellite cells. J. Cell Science 2006, 119, 1824-1832. [CrossRef] [PubMed] 
33. Smeriglio, P.; Alonso-Martin, S.; Masciarelli, S.; Madaro, L.; Iosue, I.; Marrocco, V.; Relaix, F.; Fazi, F.; Marazzi, G.; Sassoon, D.A.; et al. Phosphotyrosine phosphatase inhibitor bisperoxovanadium endows myogenic cells with enhanced muscle stem cell functions via epigenetic modulation of Sca-1 and Pw1 promoters. FASEB J. 2016, 30, 1404-1415. [CrossRef] [PubMed]

34. Conboy, I.M.; Conboy, M.J.; Smythe, G.M.; Rando, T.A. Notch-mediated restoration of regenerative potential to aged muscle. Science 2003, 302, 1575-1577. [CrossRef] [PubMed]

35. Quattrocelli, M.; Costamagna, D.; Giacomazzi, G.; Camps, J.; Sampaolesi, M. Notch signaling regulates myogenic regenerative capacity of murine and human mesoangioblasts. Cell Death Dis. 2014, 5, e1448. [CrossRef]

36. Fuoco, C.; Salvatori, M.L.; Biondo, A.; Shapira-Schweitzer, K.; Santoleri, S.; Antonini, S.; Bernardini, S.; Tedesco, F.S.; Cannata, S.; Seliktar, D.; et al. Injectable polyethylene glycol-fibrinogen hydrogel adjuvant improves survival and differentiation of transplanted mesoangioblasts in acute and chronic skeletal-muscle degeneration. Skelet. Muscle 2012, 2, 24. [CrossRef]

37. Sun, Z.; Arendt, C.W.; Ellmeier, W.; Schaeffer, E.M.; Sunshine, M.J.; Gandhi, L.; Annes, J.; Petrzilka, D.; Kupfer, A.; Schwartzberg, P.L.; et al. PKC-theta is required for TCR-induced NF-kappaB activation in mature but not immature T lymphocytes. Nature 2000, 404, 402-407. [CrossRef]

38. Saccone, V.; Consalvi, S.; Giordani, L.; Mozzetta, C.; Barozzi, I.; Sandona, M.; Ryan, T.; Rojas-Munoz, A.; Madaro, L.; Fasanaro, P.; et al. HDAC-regulated myomiRs control BAF60 variant exchange and direct the functional phenotype of fibro-adipogenic progenitors in dystrophic muscles. Genes Dev. 2014, 28, 841-857. [CrossRef]

(C) 2020 by the authors. Licensee MDPI, Basel, Switzerland. This article is an open access article distributed under the terms and conditions of the Creative Commons Attribution (CC BY) license (http://creativecommons.org/licenses/by/4.0/). 